\title{
The Sydney Heart Bank: improving translational research while eliminating or reducing the use of animal models of human heart disease
}

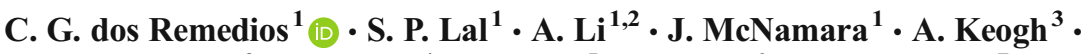 \\ P. S. Macdonald ${ }^{3}$ • R. Cooke ${ }^{4}$ E. Ehler ${ }^{5}$ - R. Knöll ${ }^{6}$ • S. B. Marston ${ }^{7} \cdot$ J. Stelzer ${ }^{8}$. \\ H. Granzier ${ }^{9}$ - C. Bezzina ${ }^{10}$ • S. van Dijk ${ }^{11}$ - F. De Man ${ }^{11}$ • G. J. M. Stienen ${ }^{11}$ • \\ J. Odeberg ${ }^{12} \cdot$ F. Pontén ${ }^{13} \cdot$ W. Linke ${ }^{14}$. J. van der Velden ${ }^{11}$
}

Received: 24 July 2017 / Accepted: 31 July 2017 /Published online: 14 August 2017

(C) International Union for Pure and Applied Biophysics (IUPAB) and Springer-Verlag GmbH Germany 2017

\begin{abstract}
The Sydney Heart Bank (SHB) is one of the largest human heart tissue banks in existence. Its mission is to provide high-quality human heart tissue for research into the molecular basis of human heart failure by working collaboratively with experts in this field. We argue that, by comparing tissues from failing human hearts with age-matched non-failing healthy donor hearts, the results will be more relevant than research using animal models, particularly if their physiology is very different from humans. Tissue from heart surgery must generally be used soon after collection or it significantly deteriorates. Freezing is an option but it raises concerns that freezing causes substantial
\end{abstract}

This article is part of a Special Issue on 'IUPAB Edinburgh Congress' edited by Damien Hall.

Electronic supplementary material The online version of this article (doi:10.1007/s12551-017-0305-3) contains supplementary material, which is available to authorized users.

\section{G. dos Remedios}

crisdos@anatomy.usyd.edu.au

1 Sydney Heart Bank, Discipline of Anatomy \& Histology, University of Sydney, Sydney, Australia

2 Department of Molecular Physiology and Biophysics, University of Vermont, Burlington, VT, USA

3 Heart Transplant Unit, St Vincent's Hospital, Sydney, Australia

4 Cardiovascular Research Institute, University of California San Francisco, California, USA

5 Cardiovascular Division, Randall Division of Cell and Molecular Biophysics, London, UK

6 Department of Medicine, Karolinska Institutet, Huddinge, Sweden

7 National Heart and Lung Institute, Imperial College London, London, UK damage at the cellular and molecular level. The SHB contains failing samples from heart transplant patients and others who provided informed consent for the use of their tissue for research. All samples are cryopreserved in liquid nitrogen within 40 min of their removal from the patient, and in less than 5$10 \mathrm{~min}$ in the case of coronary arteries and left ventricle samples. To date, the SHB has collected tissue from about 450 failing hearts ( $>15,000$ samples) from patients with a wide range of etiologies as well as increasing numbers of cardiomyectomy samples from patients with hypertrophic cardiomyopathy. The Bank also has hearts from over 120 healthy
8 Department of Physiology \& Biophysics, Case Western Reserve University, Cleveland, OH, USA

9 Molecular Cardiovascular Research Program, University of Arizona, Tucson, USA

10 Department of Experimental Cardiology, Heart Failure Research Center, Amsterdam, The Netherlands

11 Department of Physiology, Institute for Cardiovascular Research, VU University Medical Center, Amsterdam, The Netherlands

12 Department of Immunology, Genetics and Pathology, Uppsala University, Uppsala, Sweden

13 Science for Life Laboratory, KTH - Royal Institute of Technology, Stockholm, Sweden

14 Ruhr University, Bochum, Germany 
organ donors whose hearts, for a variety of reasons (mainly tissue-type incompatibility with waiting heart transplant recipients), could not be used for transplantation. Donor hearts were collected by the St Vincent's Hospital Heart and Lung transplantation team from local hospitals or within a 4-h jet flight from Sydney. They were flushed with chilled cardioplegic solution and transported to Sydney where they were quickly cryopreserved in small samples. Failing and/or donor samples have been used by more than 60 research teams around the world, and have resulted in more than 100 research papers. The tissues most commonly requested are from donor left ventricles, but right ventricles, atria, interventricular system, and coronary arteries vessels have also been reported. All tissues are stored for longterm use in liquid $\mathrm{N}$ or vapor $\left(170-180{ }^{\circ} \mathrm{C}\right)$, and are shipped under nitrogen vapor to avoid degradation of sensitive molecules such as RNAs and giant proteins. We present evidence that the availability of these human heart samples has contributed to a reduction in the use of animal models of human heart failure.

Keywords Human heart failure · Human heart tissue bank . Healthy donor human hearts $\cdot$ Reducing the use of animals in research

\section{The history of the Sydney Heart Bank}

In 1989, the corresponding author began a collaboration with Dr. Victor Chang, a pioneer of heart and lung transplant surgery in Australia, who later became Australian of the Century. Today, the Victor Chang Cardiac Research Institute immortalizes his name (https://www.victorchang.edu.au/) and continues to do world-class research. The great majority of heart samples were collected at St Vincent's Hospital surgical theaters in Sydney, where they were rapidly snap-frozen and stored at $-196{ }^{\circ} \mathrm{C}$. The collection process was not without its inconveniences, for example, hearts are invariably transplanted in the small hours of the morning when several operating theaters are available. The whole process of freezing samples from the left ventricle (LV), interventricular septum (IVS), right ventricle (RV), left and right atria, and the coronary arteries, is completed in under $40 \mathrm{~min}$ of the loss of coronary circulation (cross-clamp). The numbering system for each cryovial gives us a good idea of the time lapse between circulation and freezing.

In recent years, the Sydney Heart Bank (SHB) has applied industry best practice to the way it handles banked human tissue (Lal et al. 2015). A concise description ( two pages) of the research project is assessed by an independent SHB Board that includes international cardiac researchers, cardiologists, and cardiac surgeons who assess all requests for tissue including those in the SHB. Once Human Research Ethics approvals are in place, the University of Sydney arranges for the exchange of a Material Transfer Agreement with the receiving institution, and the tissue can then be shipped in nitrogen vapor to the collaborating laboratory. This somewhat lengthy administration ensures that all proposals are thoroughly evaluated.

\section{Quality control of the Sydney Heart Bank samples}

An early concern raised by requesting laboratories was that molecular degradation of molecules such as mRNA might rapidly occur once the coronary artery circulation ceases. It is possible that prolonged ischemia will trigger processes such as apoptosis or elicit a switch in transcription/translation of proteins.

In 1989, Victor Chang helped to resolve with this dilemma by providing a small sample of LV while it was still being perfused by the coronary arteries, i.e. immediately prior to aortic crossclamp. This enabled us to quantify proteins before the loss of coronary blood flow, and at $40 \mathrm{~min}$ (when the last sample was cryopreserved), and again $2 \mathrm{~h}$ after cross-clamp. No doubt, oxygen release from cardiomyocyte myoglobin is important during long periods of ischemia. We performed SDS PAGE gels to compare samples frozen at zero time, and at 40 and $120 \mathrm{~min}$ after cross clamp. Scans of the gel lanes revealed no detectable differences between the three samples at different gel lane loadings.

The fact that many papers have now been published using health donor samples greatly diminished reviewers' concerns over post-mortem artifacts. Interestingly, a similar time window (30 min) was recently validated using dead-body donor hearts for transplantation (Dhital et al. 2015).

Not surprisingly, some laboratories remained hesitant to use human heart samples to probe the molecular basis of human heart failure. Firstly, because, unlike in-bred mice, patients are genetically diverse, and their heart failures are often complicated by complex lifestyle choices, multiple drug regimes, and comorbidities in addition to those mentioned above. Furthermore, some of these characteristics might also apply to the donors. Initially, some assumed that the donor hearts were from postmortem bodies and therefore would be degraded during the 12$36 \mathrm{~h}$ it takes for a coroner to perform the post mortem and release the tissues for research. However, over time, our colleagues, particularly in Europe and the USA, began to use SHB samples and they soon established they were remarkably free of artifacts.

A major aim of the SHB is to create a network of collaborators with different expertise and skills who would work collectively on tissue from the same failing and/or non-failing hearts. Figure 1 identifies the names and locations of 90 research groups around the world that continue to work individually on different aspects of human heart failure (red) or have done so in the past (black) (Li et al. 2013)

\section{Testing whether data from animal models apply to humans}

Some of our first publications (Trahair et al. 1990, 1993) tested the hypotheses, based on animal models, that the failing 


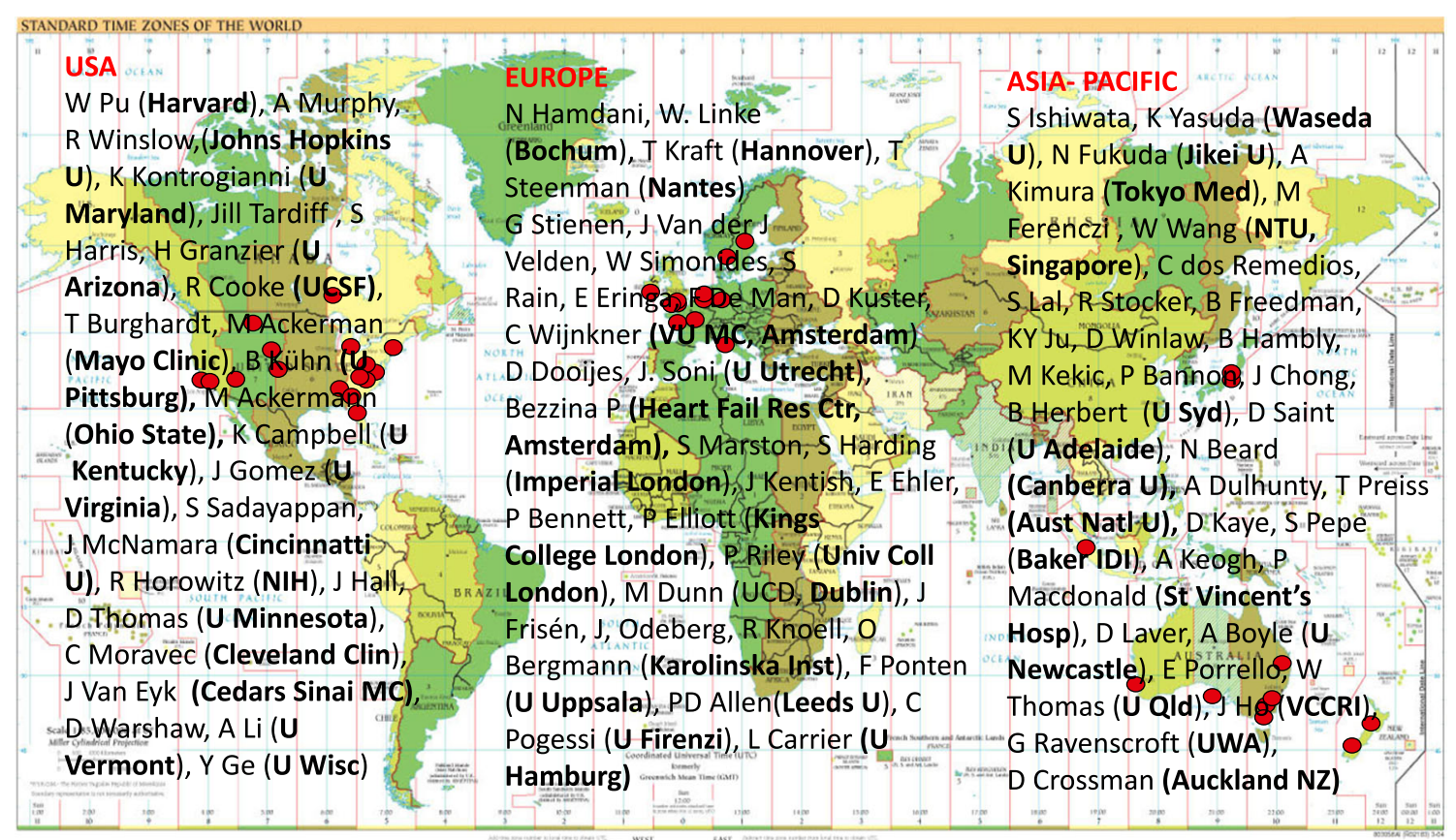

Fig. 1 A visual representation of researchers from laboratories around the world that have collaborated with the Sydney Heart Bank

heart responds by expressing embryonic genes. Northern blots did indeed confirm that the embryonic isoform of human myosin light chain 1 was up-regulated in familial heart disease. However, contrary to the expectations from the mouse model, we did not observe up-regulation in patients with non-familial dilated cardiomyopathy where the cause was idiopathic.

In another set of papers, we examined changes in expression of $\mathrm{P}_{2 \mathrm{X} 1}$ receptors in the atria of failing and healthy donors. These ATP-sensitive ligand-gated cation-selective channels were first reported in animal models, but there were no reports that they were expressed in human hearts or that there were differences between healthy and failing samples. We found that the expression of these adrenergic extracellular receptors nearly doubled in patients with idiopathic dilated cardiomyopathy compared to donors (Berry et al. 1998, 1999, 2000). Our data suggest that these purinergic receptors may be potential biomarkers for therapeutic intervention (Ralevic 2015).

More recently, we investigated a phenomenon called super-relaxation (SRX), a state in which a fraction of myosin cross-bridges in striated muscle have a greatly reduced ATPase rate. The sarcomeric protein, myosin binding protein $\mathrm{C}$, resident in myosin thick filaments, has been strongly implicated in regulating the SRX state (McNamara et al. 2015). We wanted to know if SRX occurred in human cardiac muscle and, if so, does the fraction of cross-bridges in SRX change in failing human hearts. Working with our colleagues at the University of Arizona Tucson, we used LV samples of transgenic mice carrying a mutation in the gene $M Y B P C 3$ coding for myosin binding protein $\mathrm{C}$, at the Victor Chang Cardiac Research Institute, and we found that homozygous mouse LV developed a phenotype that was a good model of human hypertrophic cardiomyopathy (HCM) but that both heterozygotes and wild-type mice were functionally normal (McNamara et al. 2016). This suggested that there must be significant differences between the heterozygous mice and humans, who are almost invariably heterozygous. We have just reported that the fraction of myosin heads in the SRX state from HCM patients is significantly lower than age-matched donors (McNamara et al. 2017).

\section{Development of a collaborative global network of researchers}

As the SHB increased in size and its reputation grew as a willing provider of high-quality tissue samples from all parts of the heart, the number of requests for tissue increased. The only expense the SHB requires of recipients is that they cover the cost of transporting samples from Sydney to their laboratory in a nitrogen-vapor dewar that maintains the temperature at about $-170{ }^{\circ} \mathrm{C}$.

Below, we summarize a selection of research papers that test the hypothesis that human heart disease is best investigated by comparing non-failing donor hearts with failing human hearts rather than relying on hearts from animal models of human heart disease. 
Apoptosis and cellular proliferation in human hearts

Yao et al. (1996) tested the hypothesis that the human heart was a terminally differentiated organ. Mouse hearts retain a limited regenerative capacity but it was thought that not even low levels of mitosis occurred in human cardiomyocytes. Jiang et al. (2001) critically reviewed the evidence for apoptosis in the human heart and concluded that apoptosis does occur, but at a very low rate. The field had to wait more than a decade for evidence that cell death was compensated for by cardiac proliferation (Mollova et al. 2013; Polizzotti et al. 2015).

\section{Discovery of a giant protein in familial dilated cardiomyopathy}

The Seidman laboratory reported that mutations in the TTN gene encoding the giant protein titin, were responsible for heart failure in patients in about a quarter of all familial dilated cardiomyopathies (FDCM) (Herman et al. 2012). Titin is by far the largest known single polypeptide chain (molecular weight $3 \mathrm{MD}, 27,000$ amino acids). It has its $\mathrm{N}$-terminus anchored in the $\mathrm{Z}$ disc and the chain extends though the I band to join the thick filaments of the $A$ band before its $C$ terminates by binding to another titin from the other half of the sarcomere. Our collaborators in Europe (Steve Marston at Imperial College London and Ralph Knöll at the Karolinska Institute in Stockholm) initiated a whole genome sequencing (confirmed by Sanger sequencing) of 25 samples from the LVs of SHB patients diagnosed with FDCM (Marston et al. 2015). Our data confirmed the Herman et al. (2012) report that mutations in titin accounted for one in five of the patients. However, the data also revealed that four patients carried point mutations in another giant protein gene, obscurin $(O B S C N)$. This protein has its $\mathrm{N}$-terminus in the central $\mathrm{M}$ line of the sarcomere where it is anchored to both myomesin and titin.

The location of its $\mathrm{C}$-terminus is still being investigated, although it is known to bind strongly to a small splice-variant of titin (Novex-3) located close to the $\mathrm{Z}$ disc (Bang et al. 2001). Work continues to investigate if obscurin is causative of FDCM and total RNA sequencing, and other analyses of titin continue in the Knöll laboratory.

No animal experiments were involved in this study.

\section{Right ventricular heart failure}

The ability of the RV to relax during diastole is impaired in patients with pulmonary arterial hypertension $(\mathrm{PAH})$ and $\mathrm{RV}$ heart failure. A collaboration between colleagues in Amsterdam, Paris, and Arizona (Rain et al. 2013) using SHB samples concluded that a combination of changes in titin stiffness, reduced cTnI phosphorylation, and altered levels of phosphorylation of $\mathrm{Ca}^{2+}$-handling proteins all contribute to RV diastolic dysfunction in PAH. The following year, Manders et al. (2014) used cardiac MRI, to show that the $\mathrm{RV}$ in PAH (both idiopathic and PAH in Eisenmengers syndrome patients) also reduces LV wall thickness, causing a $30 \%$ decrease in the ratio of myosin:actin in cardiomyocytes, and significantly reduced protein phosphorylation.

No animals were used in the above experiments.

\section{Hypertrophic Cardiomyopathy}

In hypertrophic cardiomyopathy (HCM), the most frequently affected gene is MYBPC3. van Dijk et al. (2013) compared isolated, permeabilized cardiomyocytes from healthy donors and from HCM patients with mutated MYBPC3 (expressed at $63 \%$ of donor levels). They showed that, although maximal force development was reduced, the rates of force redevelopment, stretch activation and cross-bridge kinetics did not differ significantly. This suggested that cross-bridge kinetics were not altered, a finding that was consistent with haploinsufficiency (van Dijk et al. 2013).

In another paper, Kuster et al. (2013) hypothesized that microRNAs played a role in HCM. Transcription profiling of six patients and of six aged-matched donors identified 13 miRNAs that were differentially expressed. They demonstrated changes in cardiac $\beta$-adrenergic receptor signaling as well as a reduced phosphorylation of cardiac troponin I (Narolska et al. 2006).

A European consortium (Witjas-Paalberends et al. 2014) used the SHB LV samples to study the effects of gene mutations encoding two sarcomeric proteins, cMyBP-c (C protein) and MYH7 (myosin heavy chain). They found that, while they perturb the energetic cost of contraction, non-sarcomeric mutations did not.

All of these reports were published without using animal models.

\section{Phosphorylation of proteins regulates contractile force}

A collaboration (Kooij et al. 2013) between the Jolanda van der Velden laboratory (Amsterdam), Anne Murphy's laboratory (Baltimore), and the SHB investigated whether protein kinase $\mathrm{A}(\mathrm{PKA})$ and protein kinase $\mathrm{C} \alpha(\mathrm{PKC} \alpha)$ modulate the performance of cardiomyocytes. Earlier, it had been shown that both kinases can regulate contractile force in the mouse. SHB LV samples from IDCM patients were used to show that, while PKC $\alpha$ essentially had no effect on human cardiomyocytes, PKA phosphorylates cardiac troponin I. This phosphorylation modulates the functions of other 
sarcomeric proteins including titin. This is another example of why caution is needed when translating animal-derived data to humans.

No animal models were used.

\section{Cytoskeletal proteins also play a role in human heart failure}

While others were searching in the sarcomere for proteins associated with human heart failure, Elisabeth Ehler and her colleagues used SHB heart samples to focus on cytoskeletal proteins (Pleuss et al. 2015). Confocal microscopy images show that, while FHOD1 is a component of the sarcomeres (Dwyer et al. 2015), it is mainly located at the intercalated discs, which are the tight cell-cell contacts between cardiomyocytes that are often associated with cardiomyopathies.

Ehler's group also examined a related cardiomyocyte cytoskeletal protein, FHOD3, that promotes the polymerization of sarcomeric actin, and is therefore responsible for maintaining sarcomere structural integrity (Iskratch et al. 2010). Her laboratory highlighted the role of mutations in the muscle LIM protein gene $(M L P)$ play in human hypertrophic cardiomyopathy (HCM). The LIM domain family of proteins were wellknown for their association with heart failure (Li et al. 2012). Mutations in the $M L P$ gene reduced its ability to be phosphorylated in HCM hearts (Iskratch et al. 2010). More recently, this group showed that MLP plays a role in the more common form of heart failure, namely dilated cardiomyopathy (Lange et al. 2016). It directly inhibits protein kinase $\mathrm{C}$ alpha (PKC $\alpha$ ) phosphorylation of a multiprotein complex at the intercalated discs. A murine model was used in this study.

\section{Coronary artery disease}

Myocardial infarction is a major cause of human heart failure. For many years, we have collaborated with Bill Pu's laboratory at the Boston Children's Hospital, Harvard Medical School, where they have looked at the role of RNA. The SHB provided LV samples from patients with ischemic heart disease (IHD) and healthy age-matched donor hearts to investigate whether IHD is associated with changes in RNA splicing of sarcomeric protein genes (Kong et al. 2010). Using deep RNA sequencing, they showed that long non-coding RNA (lncRNA) is differentially regulated (Huang et al. 2016). Their genome-wide transcriptome analysis confirmed that many genes, previously known to be involved in heart failure, were altered in IHD. They identified changes in a set of 35 lncRNAs that were positively correlated with genes encoding extracellular matrix (ECM) proteins that regulate fibrosis and the expression of several extracellular matrix genes. No animals were needed in these experiments.
When the heart is removed by a transplant surgeon and handed to our SHB team, the first thing we do is dissect the coronary arteries. Michael Dunn and his wife Marlene Rose had been working with the SHB for years (dos Remedios et al. 2003), and indeed they had provided us with hearts from transplantations patients carried out at the Harefield Hospital, London, that we could not obtain. None of the SHB hearts were older than 50 years. Together with Mike's team at University College Dublin, we made two contributions to understanding the underlying mechanisms in coronary artery disease (CAD). Animal models had earlier indicated that the heat shock protein (Hsp27) might protect against CAD, so he examined endothelial and smooth muscle cells in arteries from patients with $\mathrm{CAD}$ hearts and from healthy donors with no CAD. Twodimensional gel electrophoresis, Western blots and LC MS/ MS were used to show that phospho-Hsp27 does indeed protect against vascular disease, probably by stabilizing the actin cytoskeleton (Robinson et al. 2010). This was an example of how the SHB confirmed observations that were discovered using a murine model. The next year, we produced the first 2-D gel reference map of the basic proteins (Polden et al. 2011), which remains a valuable reference.

\section{Translation to clinical practice}

The following is an example of how basic research can lead to a clinical outcome. Working closely with David Kaye and his group at the Baker IDI institute in Melbourne (Maeder et al. 2011), we measured the iron content of myocardial samples from patients with advanced heart failure. We used RT PCR to monitor the expression of type 1 transferrin receptor (Tfr1) to reveal a clear link between the anemia resulting from iron depletion, and reduced expression of Tfr1. These data enabled us to establish an adverse prognosis in patients with severe (LVEF $23 \pm 10 \%$ ) heart failure.

\section{Mass screening using GWAS}

In a collaboration with Connie Bezzina in Amsterdam and her colleagues in Europe, the SHB contributed a large number of LV hearts to a large (5159) genome-wide association study (GWAS) of patients with congenital heart disease (Cordell et al. 2013). Here, the SHB contributed many of the donor hearts to a study that helped to identify the precise location on chromosome $4 \mathrm{p} 16$ that carried a significant risk of atrial septal defect (commonly known as a "hole-in-the-heart). The genotype was present in $\sim 9 \%$ of the population. The paper was reported in Nature Genetics.

The next year, we were part of another GWAS that specified a large number of chromosome loci associated with electrocardiographic traits in patients with a predisposition to cardiac arrhythmias. Identification of the underlying molecular 
mechanisms of these traits requires an interrogation of the variants for their association with transcript abundance using expression quantitative analysis locus (eQTL) analysis. We contributed 50 the total of $129 \mathrm{LV}$ samples of non-failing donor samples used in this study. The other samples were from heart biobanks in Szeged and Miami. The results provided the first comprehensive eQTL map of the human heart (Koopmann et al. 2014)

A report by Heinig et al. "Natural genetic variation of the cardiac transcriptome in non-diseased donors and patients with dilated cardiomyopathy" is currently under revision for Genome Biology. This GWAS strategy focused on dilated cardiomyopathy, which, although usually classified as idiopathic, we now know to be substantially familial.

None of the above reports involved the use of experimental animals.

\section{Novel research capabilities from the Sydney Heart Bank}

Fredrik Pontén at Uppsala University, working with Jacob Odeberg together with Mathias Uhlén's many Swedish colleagues, developed an online, searchable facility that can probe a very large number of human tissues, including nonfailing human LV. The facility is called the Human Protein Atlas (HPA) and has developed an atlas of 25,682 antibodies that targets 16,998 unique human proteins. Each month, these numbers continue to grow. From the point of view of human heart failure, this is an amazing facility because it enables us to search about 17,000 genes for expression in the human heart. Because the HPA is based on immunohistochemistry, it is now possible to examine healthy human LV and identify not only if it is gene of interest expressed in the human heart but also see if that expression in localized in cardiomyocytes or in any of the many other cells in that tissue. The HPA only uses rabbit polyclonal antibodies that are column-purified against synthetic peptide epitopes. This is how the HPA website (http:// www.proteinatlas.org/) works (Uhlén et al. 2015) (Fig. 2).

Type http://www.proteinatlas.org/ into your web browser and in the pop-up dialog box type a protein of interest, for example "obscurin". This protein has been identified as a potential cause of FDCM (Marston et al. 2015). The search identified "OBSCN" in the gene column. Now select the "TISSUE" heading and the browser will read: http://www. proteinatlas.org/ENSG00000154358-OBSCN/tissue. Click on the "Muscle" tissue tab and select "Heart" from the drop-down menu. Now the browser will read: "http://www. proteinatlas.org/ENSG00000154358-OBSCN/tissue/heart+ muscle\#img" and six 5-mm-diameter donor LV tissue cores appear together with an indication of the level of expression based on immunohistochemistry (IHC). The search identified two anti-obscurin antibodies and we show antibody HPA019497. Thus, with a few strokes of the keyboard, you can determine if any of 17,000 genes are expressed in LV donor cardiomyocytes. By double-clicking any one of the IHC images, the magnification can be increased and the cursor can be navigated around the section. The magnified view (not shown) reveals that the anti-obscurin antibody is associated with both the sarcomeres (fine myofibrillar striations in the magnified image), and with the intercalated discs (dense brown-staining structures that connect adjacent cardiomyocytes. This is powerful information and it is free.

\section{Donor hearts}

The most common request for tissue from the SHB is for our healthy donor hearts. This is because other heart tissue repositories probably have adequate access to failing heart samples but not age-/sex-matched donor hearts. Indeed, it took us nearly two decades before the numbers of donors reached statistically useful numbers to cover the ages 0-65 years. Today, we have more than 120 donors with an age distribution from a few months through to more than 65 years.

We argue that these donors are not "controls" in the usual experimental sense where the experiment changes by only one parameter from the control. Compared to mouse controls, our donors are the antithesis of an in-bred mouse line on a controlled diet and environment. Donors are not usually accompanied by information on family history of cardiac disease, on the amount or type of medication, and of course they are genetically diverse. Donors can arise from a number of situations including motor vehicle accidents, hangings, drownings, and a range of other circumstances such as massive cerebral hemorrhage. Most have no history of heart disease and are apparently asymptomatic. When we get them, they invariably have been perfused with cold cardioplegia and have been transported sterile on ice.

In one sense, they are relevant to the study of cardiomyopathies because their diversity reflects the diversity of the heart transplant patients. No donors are retrieved if it would take more than $4 \mathrm{~h}$ to arrive and be ready for the transplant surgeon. As discussed above, our donor hearts are definitely not post mortem. However, when we began urging researchers to directly investigate human hearts, many were reluctant to spend time and funds on hearts that were ill-defined. For example, Wolfgang Linke and his group work on the giant protein titin which is very sensitive to even very low levels of proteases, so they reasonably assumed that only biopsy samples were likely to be free of degradation. Thus, several years passed before it was discovered (Krüger et al. 2009; Hamdani et al. 2013; Koetter et al. 2013) that the titin in our donors were indeed free of proteolysis. RNAs are also highly sensitive to hydrolysis, but several colleagues have used LV samples from failing and donors with good results including Kuster et al. (2013), Kong et al. (2010) and Huang et al. (2016).

A more serious problem arises when our colleagues submit their papers to journals and then have to deal with critical 
Fig. 2 This image was copied (with permission) from the Human Protein Atlas (HPA) website (proteinaltas.org). It shows the immunohistochemical identification of the HPA antibody, HPA019497) with the intercalated discs of healthy donor human left ventricle

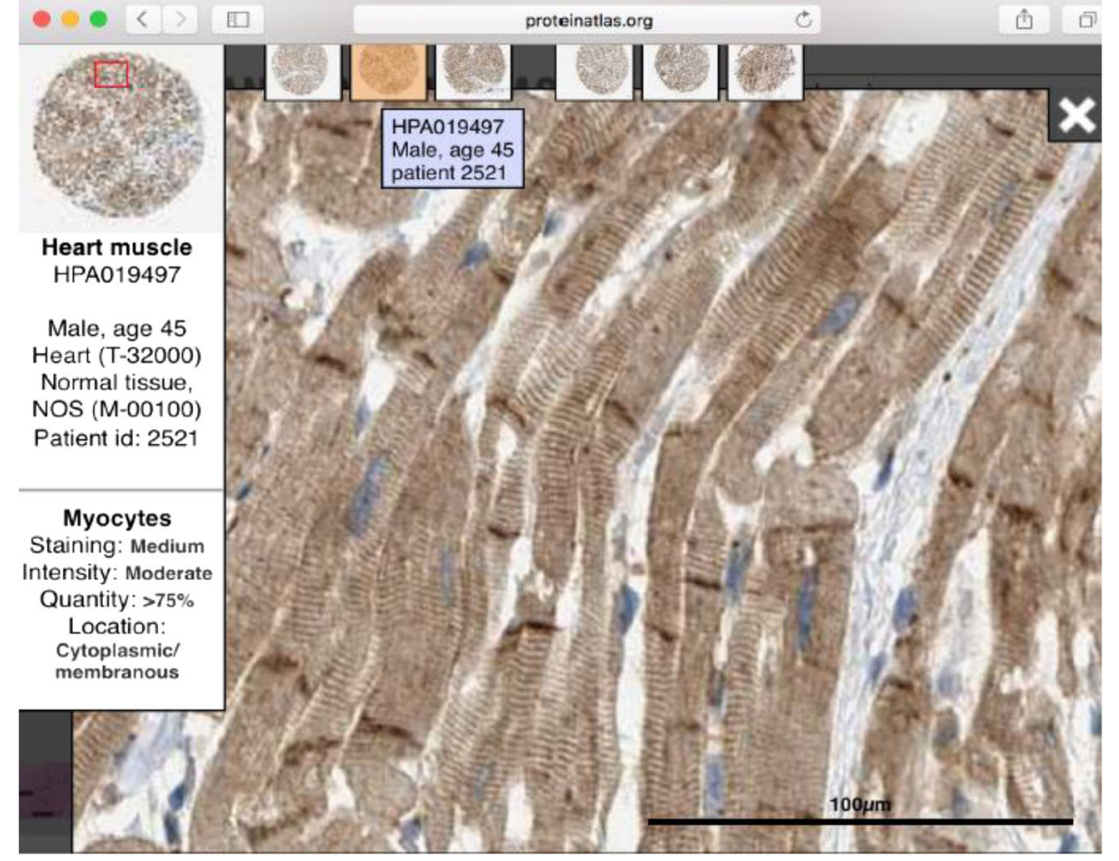

comments concerning the selection of "good" quality donor hearts. We have developed a response that appeases such referees by pointing out that all or at least many of the donor hearts have already been used in publications as "healthy", and it is for that reason that we request that the sample codes of all heart samples used in publications be either quoted in the paper's methods, or privately provide them to the SHB so we can distribute this information to other recipients from the same hearts.

\section{SHB tissue can replace mice in experimental drug testing}

We recently published a report (Mamidi et al. 2015) using cryopreserved SHB LV tissue shipped under nitrogen vapor to Julian Stelzer's laboratory at Case Western Reserve University. They used it to examine the effects of the experimental activator of myosin, omecamtiv mecarbil (OM), and found it significantly increased the rate of force generation in chemically-skinned LV cardiomyocytes at low levels of Ca ion sensitivity. Furthermore, kinetic (stretch-activated force development) analyses of cardiac muscle fibers showed that OM recruits myosin cross-bridges into the force-producing state.

This report involved the use of six transgenic and six wildtype mice.

Transgenic knock-out mice and wild-type controls have been used to test $\mathrm{OM}$ on a range of experimental animals but this is the first report of its use on human non-failing (donor) cardiomyocytes. A subsequent paper ("Dose-dependent effects of the myosin activator omercamtiv mecarbil on cross-bridge behavior and force development in failing human myocardium" by Mamidi et al. is currently under revision, and does not involve animals. This will be the first report of the effects of OM on failing human cardiomyocytes. No experimental animals were used in this report.

\section{Animal models of human heart disease are poor predictors of human heart disease}

In 2013, an editorial in Nature Medicine highlighted how poorly murine models reflect human disease, specifically the inflammatory response of humans compared to mice (Seoka et al. 2013). In a recent report, we echoed this conclusion (Lal et al. 2016a), and here we summarize new evidence.

Clearly, mouse hearts are substantially different from human hearts. Mice express a fast myosin isoform and they have a resting heart rate of 400-600 beats per minute compared to the human heart rate of $60-80$ beats per minute. There is no doubt there are examples where mice and other animals have provided valuable information on molecular defects in human hearts, but there are also examples when the mouse model is simply confounding. This review of data obtained using the SHB tissue in concert with our many collaborators suggests that, rather than go straight to an animal models, researchers should first consider directly interrogating human failing and non-failing heart samples.

For instance, a paper by McNamara et al. (2016) used LV from a transgenic mouse carrying a mutation in the protein, Myosin Binding Protein C (MYBPC). This heart sample was sent to us by collaborators in at the University of Arizona for an entirely different purpose. Our aim was to see if mutations in this gene altered the population of functional myosin crossbridges known as SRX that had been documented using several animal models (McNamara et al. 2015). The phenotype of 


\section{Sydney Heart Bank, 10 year Publication and Citation rates}

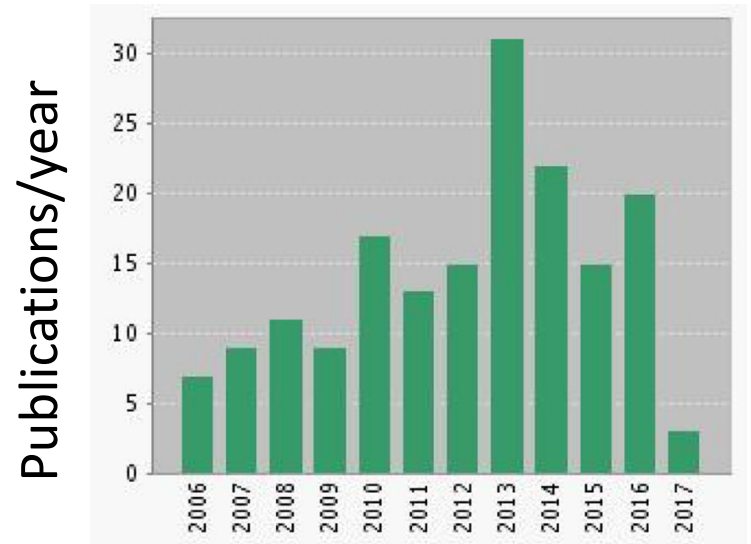

Fig. 3 The above discussion implies that the scientific output by the Sydney Heart Bank should increase as both the number of collaborators grew. This figure shows that both the number of publications and the

the homozygous mice did indeed have a reduced number of SRX cross-bridges compared to the wild-type mice. However, the heterozygotes were essentially the same as the wild-type controls. We then carried out the SRX experiments using our donor hearts as "controls" and compared them with patients who carried mutated $M Y B P C$ and were heterozygous. The result was a significant decrease in the population of SRX myosin cross-bridges in HCM patients carrying a mutation in MYBPC (McNamara et al. 2017).

It took more than a decade (from 1989 to 2000) to assemble sufficient numbers of human failing and non-failing donor hearts to achieve statistical certainty. Patients who consented to the use of their heart tissue for research had co-morbidities and complex medication, and they were necessarily at the endstage of medical intervention. Figure 3 plots the publication

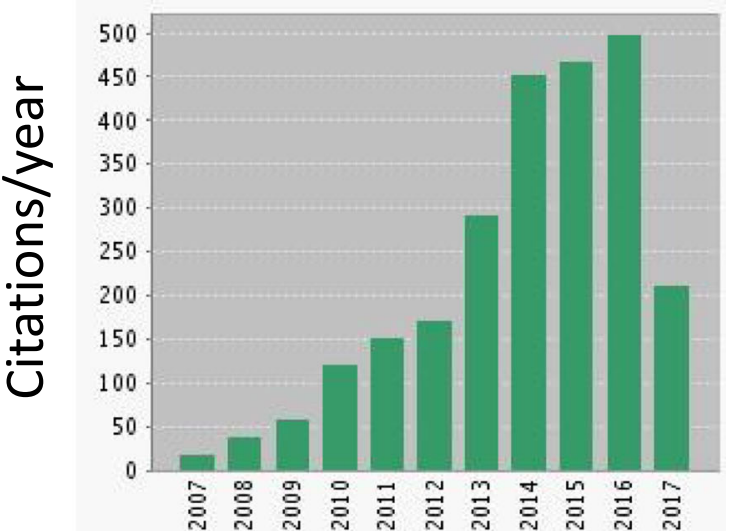

number of citations increased during the past decade. The data were derived from the Web of Science

rates and citation rates of these publication based on information extracted from the Web of Science. The figure suggests that both rates grew as we collaborated with scores of collaborators.

\section{Cardiomyectomy of patients with hypertrophic Cardiomyopathy}

We recognize that by studying end-stage human heart failure we are unable to address changes in the myocardium that lead to the end-stage state. HCM commonly involves hypertrophy of the interventricular septum (IVS) which restricts the outflow of blood from the LV. Surgical resection (cardiomyectomy) of the left side of the IVS is increasingly used to correct this obstruction, and the tissue (often gram
Fig. 4 This schematic flow chart shows the connections between the Sydney Heart Bank (blue) and seven classes of heart failure using statistically significant numbers of patient types (brown), where specific cell types or whole tissue was involved (red), and where the type of investigations (green) involved sarcomeric, cytoplasmic proteins, or cardiomyocyte membranes (blue) that resulted in publications based on the topics listed (purple). The papers arising and their citations are detailed in Fig. 3

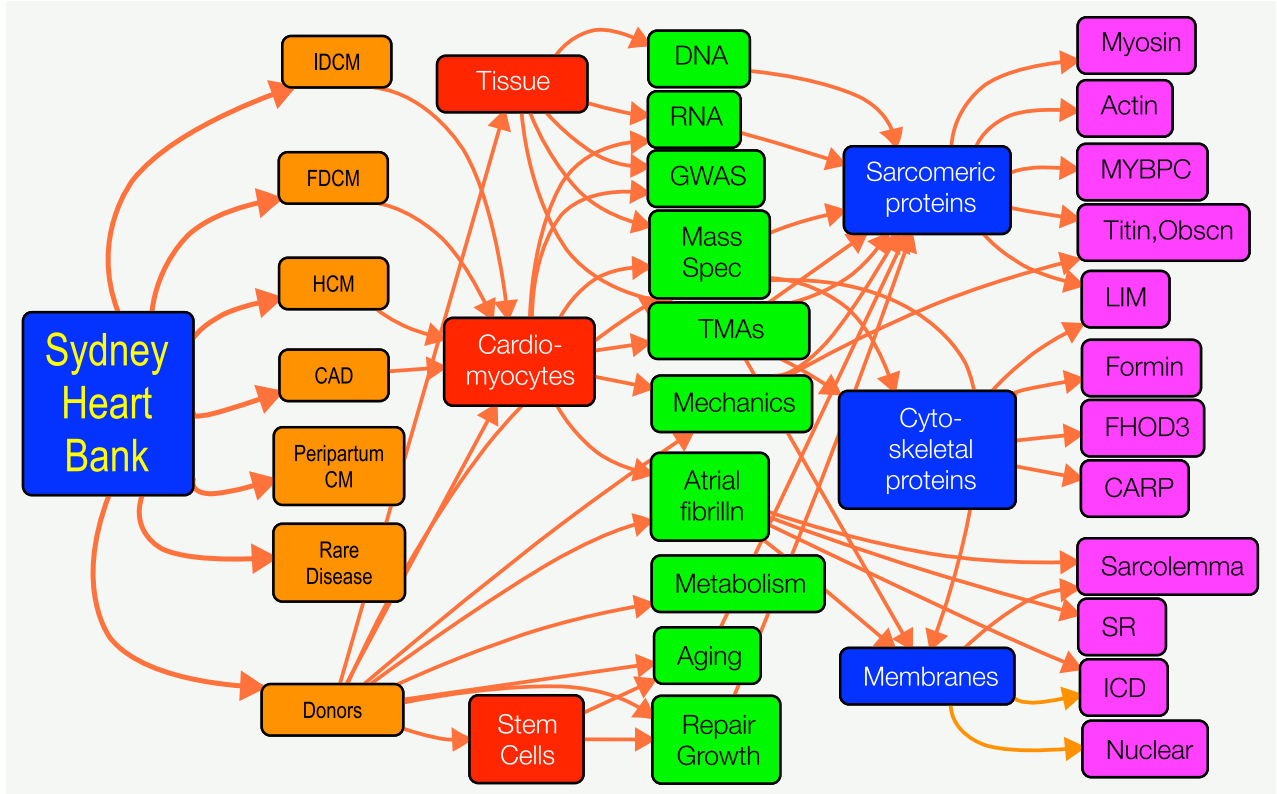


quantities) can be obtained with appropriate human ethics approval by the patient.

One of the most common causes of human heart failure is coronary artery disease. This can be treated by coronary artery by-pass graft surgery, and is also capable of yielding small (mg) amounts of tissue. Even small biopsy amounts of tissue can be investigated by whole genome and total RNA sequencing, as well as mass spectrometry. Thus, the SHB expects to be able to incrementally assemble a wider range of cardiomyopathy samples from pre-end-stage heart failure.

There is no doubt that animal models have led to new insights into the nature of human heart failure. Here, we ask the question: Has the SHB been successful in generating new and useful science? We can point to over 100 papers published in high-impact journals, but have these had an impact on the field? One measure of the impact of these papers, many of which are cited in the above discussion, is to examine the citation rates of publications using SHB tissue.

\section{Summary of the Sydney Heart Bank research}

The SHB works on the assumption that no scientist would deliberately kill animals for research if there was an alternative. Figures 1 and 4 provide an overview of the diversity of researchers and research areas covered by SHB where we have either minimized the use of animals as models of human heart failure or eliminated them entirely. The complete list of papers can be found in the Supplementary references. It is clear that there is much work to be carried out in understanding the molecular basis of human heart failure, but this is a good start.

The sheer size of the SHB has enabled it to contribute to projects aimed at produced a large and growing bank of data on heart failure that can be accessed by the entire research community. Our contributions to GWAS have provided new insights into multiple congenital diseases phenotypes (Cordell et al. 2013), the vulnerability of patients with IHD to arrhythmias and conduction defects (Marsman et al. 2014), and more recently into the natural variations in the transcriptomes comparing LV samples from donor hearts with sample from patients with dilated cardiomyopathy (Heinig et al. Genome Biology under review). Our studies of RNA splicing of sarcomere genes contributed to a better understanding of heart failure (Kong et al. 2010) as did our report on the microRNA transcriptome profiling of patients with hypertrophic cardiomyopathy.

At the protein level, we have contributed a basic protein reference map of donor LV. Also, now underway, is a large study of 14 cases of dilated cardiomyopathy with diabetes, 14 cases of dilated cardiomyopathy with no diabetes, and 31 agematched healthy donor hearts in which we will examine each of the four heart chambers using mass spectrometry of human cardiac myofilaments (Peng et al. 2014). The SHB also provides screening tools for immunohistochemical screening of failing and donor human hearts using Tissue Microarray technology (Lal et al. 2016b).

The SHB expects to continue collecting human heart tissue, particularly from patients prior to end-stage failure, and to assist in the very large process of understanding heart failure at the molecular level.

Acknowledgements Sean Lal, Amy Li and Cris dos Remedios acknowledge the important contributions of present and former members of the Muscle Research Unit and Heart Research laboratories for their contributions to the collection, documentation and cataloging of human heart samples and data with the collaboration of the surgeons and cardiologists of St Vincent's Hospital in Sydney over the past 29 years. We particularly acknowledge the contribution of Mr Darryl Cameron in producing the human tissue microarrays. We also acknowledge the grant support provided by Medical Advances Without Animals (MAWA).

\section{Compliance with ethical standards}

Conflicts of interest CG dos Remedios declares that he has no conflicts of interest. SP Lal declares that he has no conflicts of interest. J McNamara declares that he has no conflicts of interest. A Keogh declares that she has no conflicts of interest. PS Macdonald declares that he has no conflicts of interest. R Cooke declares that he has no conflicts of interest. E Ehler declares that she has no conflicts of interest. R Knöll declares that he has no conflicts of interest. SB Marston declares that he has no conflicts of interest. J Stelzer declares that he has no conflicts of interest. H Granzier declares that he has no conflicts of interest. C Bezzina declares that she has no conflicts of interest. S van Dijk declares that she has no conflicts of interest. F De Man declares that she has no conflicts of interest. GJM Stienen declares that he has no conflicts of interest. J Odeberg declares that he has no conflicts of interest. F Pontén declares that he has no conflicts of interest. W Linke declares that he has no conflicts of interest. J van der Velden declares that she has no conflicts of interest.

Ethical approval This article does not contain any studies with human participants or animals performed by any of the authors.

\section{References}

Bang ML, Centner T, Fornoff F, Geach AJ, Gotthardt M, McNabb M, Witt CC, Labeit D, Gregorio CC, Granzier H, Labeit S (2001) The complete gene sequence of titin, expression of an unusual approximately $700-\mathrm{kDa}$ titin isoform, and its interaction with obscurin identify a novel Z-line to I-band linking system. Circ Res 89:1065-1072

Berry D, Yao M, Barden JA, Balcar VJ, Hansen MA, Bennett MR, Keogh A, dos Remedios CG (1998) Alterations in the expression of P2X1 receptors in failing and non-diseased human atria. Electrophoresis 19:856-859

Berry D, Barden JA, Balcar VJ, Keogh A, dos Remedios CG (1999) Increase in expression of $\mathrm{P} 2 \mathrm{X} 1$ receptors in the atria of patients suffering from dilated cardiomyopathy. Electrophoresis 20:2059 2064

Berry D, Balcar VJ, Barden JA, Keogh A, dos Remedios CG (2000) Changes in P2X1 receptors in human left ventricles and their relationship to the acto-ATPase $\alpha$-sarcoglycan (adhalin). Electrophoresis 17: 3857-3862

Cordell HJ, Bentham J, Topf A, Zelenika D, Heath S, Mamasoula C, Cosgrove C, Blue G, Granados-Riveron J, Setchfield K, Thornborough C, Breckpot J, Soemedi R, Martin R, Rahman TJ, Hall D, van Engelen K, Moorman AF, Zwinderman AH, Barnett P, 
Koopmann TT, Adriaens ME, Varro A, George AL Jr, dos Remedios C, Bishopric NH, Bezzina CR, O’Sullivan J, Gewillig M, Bu'lock FA, Winlaw D, Bhattacharya S, Devriendt K, Brook JD, Mulder BJ, Mital S, Postma AV, Lathrop GM, Farrall M, Goodship JA, Keavney BD (2013) Genome-wide association study of multiple congenital heart disease phenotypes identifies a susceptibility locus for atrial septal defect at chromosome 4p16. Nat Genet 45:822-824

Dhital KK, Iyer A, Connellan M, Chew HC, Gao L, Doyle A, Hicks M, Kumarasinghe G, Soto C, Dinale A, Cartwright B, Nair P, Granger E, Jansz P, Jabbour A, Kotlyar E, Keogh A, Hayward C, Graham R, Spratt P, Macdonald P (2015) Adult heart transplantation with distant procurement and ex-vivo preservation of donor hearts after circulatory death: a case series. Lancet 385:2585-2591. doi:10.1016/ S0140-6736(15)60038-1

dos Remedios CG, Liew CC, Allen PD, Winslow RL, Van Eyk JE, Dunn MJ (2003) Genomics, proteomics and bioinformatics of human heart failure. J Muscle Res Cell Motil 24:251-260

Dwyer J, Pluess M, Iskratsch T, dos Remedios CG, Ehler E (2015) The formin FHOD1 in cardiomyocytes. Anat Rec 297:1560-1570

Hamdani N, Krysiak J, Kreusser MM, Neef S, Dos Remedios CG, Maier LS, Krüger M, Backs J, Linke WA (2013) Crucial role for Ca2+/ calmodulin dependent protein kinase-II in regulating diastolic stress of normal and failing hearts via titin phosphorylation. Circ Res 112: 664-674

Herman DS, Lam L, Taylor MRG, Wang L, Teekakirikul P, Christodoulou D, Conner L, DePalma SR, McDonough B, Sparks E, Teodorescu DL, Cirino AL, Banner NR, Pennell DJ, Graw S, Merlo M, Di Lenarda A, Sinatra G, Bos JM, Ackerman MJ, Mitchell RN, Murry CE, Lakdawala NK, Ho CY, Barton PJR, Cook SA, Mestroni L, Weidman JG, Seidman CE (2012) Truncations of titian causing cardiomyopathy. N Engl J Med 3667: 619-628

Huang Z-P, Yan Ding Jinghai Y, Chen J, Wu G, Kataoka M, Hu Y, Yang J-H, Liu J, Drakos SG, Selzman CH, Kyselovic J, Qu L-H, dos Remedios CG, Pu WT, Wang D-Z (2016) Long non-coding RNAs link extracellular matrix gene expression to ischemic cardiomyopathy. Cardiovasc Res. doi:10.1093/cvr/cvw201

Iskratsch T, Lange S, Dwyer J, Kho A. dos Remedios C, Ehler E (2010) Formin follows function: a muscle-specific isoform of FHOD3 is regulatedby $\mathrm{CK} 2$ phosphorylation and promotes myofibril maintenance. J CellBiol 191:1159-1172

Jiang L, Tsubakihara M, Heinke MY, Yao M, Keogh A, dos Remedios CG, Nosworthy N (2001) Heart failure and apoptosis: electrophoretic methods support data from micro- and macro-arrays: a critical review of genomics and proteomics. Proteomics 1:1481-1488

Koetter S, Gout L, Von Frieling-Salewsky M, Müller AE, Helling S, Marcus K, Dos Remedios C, Linke WA, Krüger M (2013) Differential changes in titin domain phosphorylation increase myofilament stiffness in failing human hearts. Cardiovasc Res 99:648656

Kong SW, Hu Y, Ho J, Ikeda S, Polster S, John R, Hall JL, Bisping E, Pieske B, dos Remedios CG, Pu WT (2010) Heart failure associated changes in RNA splicing of sarcomere genes. Circ Cardiovasc Genet 3:138-146. doi:10.1161/CIRCGENETICS.109.904698

Kooij V, Zhang P, Piersma SR, Sequeira V, Boontje NM, Wijnker PJM, Jiménez KE, dos Remedios C, Murphy AM, Van Eyk JE, van der Velden J, Stienen GJM (2013) PKC $\alpha$-specific phosphorylation of the troponin complex in human myocardium: a functional and proteomics analysis. PLoS ONE 8:e74847. doi:10.1371/journal.pone. 0074847

Koopmann T, Adriaens M, Moerland P, Marsman R, Westerveld M, Lal S, Zhang T, Simmons C, Baczko I, dos Remedios C, Bishopric N, Varro A, George A, Lodder E, Bezzina C (2014) Genome-wide identification of expression quantitative trait loci (eQTLs) in human heart. PLoS ONE 9:e97380. doi:10.1371/journal.pone.0097380
Krüger M, Kötter S, Grützner A, Lang P, Andresen C, Redfield MM, Butt E, Dos Remedios CG, Linke WA (2009) Protein kinase G modulates human myocardial passive stiffness by phosphorylation of the titin springs. Circ Res 104:87-94

Kuster DW, Mulders J, Ten Cate FJ, Michels M, dos Remedios CG, da Costa Martins PA, van der Velden J, Oudejans CB (2013) MicroRNA transcriptome profiling in cardiac tissue of hypertrophic cardiomyopathy patients with MYBPC3 mutations. J Mol Cell Cardiol 65:59-66

Lal S, Li A, Allen D, Allen PD, Bannon P, Cartmill T, Cooke R, Farnsworth A, Keogh A, dos Remedios C (2015) Best practice biobanking of human heart tissue. Biophys Rev 7:399-406. doi: 10.1007/s12551-015-0182-6

Lal S, Li A, dos Remedios C (2016a) Limitations in translating animal studies to humans in cardiovascular disease. J Cardiovasc Transl Res 9:165-166. doi:10.1007/s12265-016-9676-2

Lal S, Nguyen L, Tezone R, Ponten F, Odeberg J, Li A, dos Remedios C (2016b) Tissue microarray (TMA) profiling in human heart failure. Proteomics 16:2319-2326. doi:10.1002/pmic.201600135

Lange S, Gehmlich K, Lun AS, Blondelle J, Hooper C, Dalton ND, Alvarez EA, Zhang X, Bang ML, Abassi YA, dos Remedios CG, Peterson KL, Chen J, Ehler E (2016) MLP and CARP are linked to chronic $\mathrm{PKC} \alpha$ signaling in dilated cardiomyopathy. Nat Commun 7: 12120. doi: $10.1038 /$ ncomms 12120

Li A, Ponten F, dos Remedios CG (2012) The interactome of LIM domain proteins: the contributions of LIM domain proteins to heart failure and heart development. Proteomics 12:203-225

Li A, Estigoy C, Raftery M, Cameron D, Odeberg J, Ponten F, Lal S, dos Remedios CG (2013) Heart research advances using database search engines, human protein atlas and the Sydney Heart Bank. Heart Lung Circ 22:819-826

Maeder M, Khammy O, dos Remedios C, Kaye D (2011) Myocardial and systemic iron depletion in heart failure implications for anemia accompanying heart failure. J Am Coll Cardiol 58:474-480

Mamidi R, Gresham KS, Li A, dos Remedios CG, Stelzer JE (2015) Molecular effects of the myosin activator omecamtiv mecarbil on contractile properties of skinned myocardium lacking cardiac myosin binding protein-C. J Mol Cell Cardiol 85:262-272. doi:10.1016/ j.yjmec. 2015.06.011

Manders E, Bogaard H-J, Handoko ML, van de Veerdonk M, Keogh A, Westerhof N, Stienen GJM, dos Remedios CG, Humbert M, Dorfmüller P, Fadel E, Guignabert C, van der Velden J, VonkNoordegraaf A, de Man FS, Ottenheijm CAC (2014) Contractile dysfunction of left ventricular cardiomyocytes in patients with pulmonary arterial hypertension. J Am Coll Cardiol 64:28-37

Marsman RF, Bezzina CR, Freiberg F, Verkerk AO, Adriaens ME, Podliesna S, Chen C, Purfürst B, Spallek B, Koopmann TT, Baczko I, Dos Remedios CG, George AL Jr, Bishopric NH, Lodder EM, de Bakker JM, Fischer R, Coronel R, Wilde AA, Gotthardt M, Remme CA (2014) Coxsackie and adenovirus receptor is a modifier of cardiac conduction and arrhythmia vulnerability in the setting of myocardial ischemia. J Am Coll Cardiol 63(6):549559

Marston S, Montgiraud C, Munster AB, Copeland O, Onjee C, dos Remedios C, Messer AE, Ehler E, Knöll R (2015) OBSCN mutations associated with dilated cardiomyopathy and haploinsufficiency. PLoS ONE 10:e0138568. doi:10.1371/journal. pone. 0138568

McNamara JW, Li A, dos Remedios CG, Cooke R (2015) The role of super-relaxed myosin in skeletal and cardiac muscle. Biophys Rev $7: 5-14$

McNamara J, Li A, Smith NJ, Lal S, Graham RM, Kooiker KB, van Dijk SJ, Remedios CG, Harris SP, Cooke R (2016) Ablation of cardiac myosin binding protein-C disrupts the super-relaxed state of myosin in murine cardiomyocytes. J Mol Cell Cardiol 94:65-71. doi:10. 1016/j.yjmcc.2016.03.009 
McNamara JW, Li A, Lal S, Bos JM, Harris SP, van der Velden J, Ackerman MJ, Cooke R, dos Remedios CG (2017) MYBPC3 mutations are associated with a reduced super-relaxed state in patients with hypertrophic cardiomyopathy. PLoS ONE 12:e0180064. doi: 10.1371/journal.pone.0180064

Mollova M, Bersell K, Walsh S, Savla J, Das LT, Park SY, Silberstein LE, dos Remedios CG, Graham D, Colan S, Kühn B (2013) Cardiomyocyte proliferation contributes to heart growth in young humans. Proc Natl Acad Sci U S A 110:1446-1451

Narolska NA, Piroddi N, Belus A, Boontje NM, Scellini B, Deppemann S, Zaremba R, Musters RJ, dos Remedios CG, Jaquet K, Foster DB, Murphy AM, van Eyk JE, Tesi C, Poggesi C, van der Velden J, Stienen GJM (2006) Impaired diastolic function after exchange of endogenous troponin I with C-terminal truncated troponin I in human cardiac muscle. Circ Res 99:1012-1020

Peng Y, Ayaz-Guner S, Yu D, Ge Y (2014) Top-down mass spectrometry of cardiac myofilament proteins in health and disease. Proteomics Clin Appl 8:554-568. doi:10.1002/prca.201400043

Pleuss M, Daeubler G, dos Remedios CG, Ehler E (2015) Adaptations of cytoarchitecture in human dilated cardiomyopathy. Biophys Rev 7: 25-32. doi:10.1007/s12551-014-0146-2

Polden J, McManus CA, dos Remedios C, Dunn MJ (2011) A 2-D gel reference map of the basic human heart proteome. Proteomics 11: $3582-3586$

Polizzotti BD, Ganapathy B, Walsh S, Choudhury S, Ammanamanchi N, Bennett DG, dos Remedios CG, Haubner BJ, Penninger JM, Kühn B (2015) Stimulation of cardiomyocyte regeneration in neonatal mice and in human myocardium with neuregulin reveals a therapeutic window. Sci Transl Med 7. doi:10.1126/scitranslmed.aaa5171

Rain S, Handoko ML, Westerhof N, Stienen GJM, Paulus WJ, Ottenheijm CAC, Marcus JT, Dorfmuller P, Guignabert C, Humbert M, McDonald P, dos Remedios CG, Postmus PE, VonkNoordegraaf A, Van der Velden J, De Man FS (2013) Right ventricular diastolic impairment in patients with pulmonary arterial hypertension. Circulation 128:2016-2025

Ralevic V (2015) P2X receptors in the cardiovascular system and their potential as therapeutic targets in disease. Curr Med Chem 22:851865

Robinson AA, Dunn MJ, McCormack A, dos Remedios CG, Rose ML (2010) Protective effect of phosphorylated Hsp27 in coronary arteries through actin stabilization. J Mol Cell Cardiol 49:370-379

Seoka J, Warren HS, Cuenca AG, Mindrinos MN, Baker HV, Xu W, Richards DR, McDonald-Smith GP, Gao H, Hennessy L, Finnerty
CC, López CM, Honari S, Moore EE, Minei JP, Cuschieri J, Bankey PE, Johnson JL, Sperry J, Nathens AB, Billiar TR, West MA, Jeschke MG, Klein MB, Gamelli RL, Gibran NS, Brownstein BH, Miller-Graziano C, Calvano SE, Mason PH, Cobb JP, Rahme LG, Lowry SF, Maier RV, Moldawer LL, Herndon DN, Davis RW, Xiao W, Tompkins RG, Inflammation and Host Response to Injury, Large Scale Collaborative Research Program (2013) Genomic responses in mouse models poorly mimic human inflammatory diseases. Proc Natl Acad Sci U S A 110:3507-3512. doi:10.1073/pnas. 1222878110

Trahair T, Yeoh T, Cartmill T, Chang V, Gunning P, dos Remedios CG (1990) Is atrial myosin light chain 1 a marker of end stage failure in dilated cardiomyopathy? In: Marechál M (ed) Cell motility. Intercept, Hampshire, pp 181-187

Trahair T, Yeoh T, Cartmill T, Keogh A, Spratt P, Chang V, dos Remedios CG, Gunning P (1993) Myosin light chain gene expression associated with diseased states of the human heart. J Mol Cell Cardiol 26: 577-585. doi:10.1006/jmcc.1993.1067

Uhlén M, Fagerberg L, Hallström BM, Lindskog C, Oksvold P, Mardinoglu A, Sivertsson A, Kampf C, Sjöstedt E, Asplund A, Olsson IM, Edlund K, Lundberg E, Navani S, Szigyart CA-K, Odeberg J, Djureinovic D, Takanen JO, Hober S, Alm T, Edqvist P-H, Berling H, Hanna Tegel H, Mulder J, Rockberg J, Nilsson P, Schwenk JM, Hamsten M, von Feilitzen K, Forsberg M, Persson L, Johansson F, Zwahlen M, von Heijne G, Nielsen J, Pontén F (2015) Tissue-based map of the human proteome. Science 347:1260419. doi:10.1126/science.1260419

van Dijk SJ, Boontje NM, Heymans MW, ten Cat FJ, Michels M, dos Remedios C, Dooijes D, van Slegtenhorst MA, van der Velden J, Stienen GJM (2013) Preserved cross-bridge kinetics in human hypertrophic cardiomyopathy patients with $M Y B P C 3$ mutations. Pflugers Arch - Eur J Physiol 466:1619-1633

Witjas-Paalberends ER, Güçlü A, Germans T, Knaapen P, Harms HJ, Vermeer AMC, Christiaans I, Wilde AAM, dos Remedios C, Lammertsma AA, van Rossum AC, Stienen GJM, van Slegtenhorst M, Schinkel AF, Michels M, Ho CY, Poggesi C, van der Velden J (2014) Gene-specific increase in energetic cost of contraction in hypertrophic cardiomyopathy caused by thick filament mutations. Cardiovasc Res 103:248-257

Yao M, Keogh A, Spratt P, dos Remedios CG, Kiessling PC (1996) Elevated DNase I levels in human idiopathic dilated cardiomyopathy: an indicator of apoptosis? J Mol Cell Cardiol 28:95-101 